\title{
The Serotonin Reuptake Inhibitor Fluoxetine Reduces Sex Steroid-Related Aggression in Female Rats: An Animal Model of Premenstrual Irritability?
}

Hoi-Por Ho, M.S., Marie Olsson, M.Pharm., Lars Westberg, B.S., Jonas Melke, M.S., and Elias Eriksson, Ph.D.

The aggressive behavior displayed by some (but not all) female Wistar rats when an unfamiliar rat is being introduced into their home cage (the resident intruder paradigm) was found to be higher in non-receptive phases (metestrus, diestrus) than in the receptive phases (proestrus, estrus) of the estrus cycle, and effectively reduced by ovariectomy. When removal of the ovaries was followed by administration of estradiol and progesterone, in a regimen mimicking the normal cyclical release of these hormones, aggressive behavior was elicited, two days after estrus, in animals that had displayed aggressive behavior before ovariectomy, but not in those that had not. Short- term administration of a serotonin reuptake inhibitor (fluoxetine hydrochloride; $10 \mathrm{mg} / \mathrm{kg}$, i.p.; 4-5 days) reduced both the aggressive behavior displayed during the diestrus phase by normally cycling rats, and the aggressive behavior elicited by administration of estradiol plus progesterone after ovariectomy. It is suggested that the aggressive behavior displayed by the female Wistar rat in the resident intruder paradigm may serve as an animal model of premenstrual dysphoria.

[Neuropsychopharmacology 24:502-510, 2001] (C) 2001 American College of Neuropsychopharmacology. Published by Elsevier Science Inc.
KEY WORDS: Aggression; Irritability; Estrus cycle; Resident intruder paradigm; Serotonin; Serotonin reuptake inhibitor; Fluoxetine; Premenstrual dysphoria; Rat

Premenstrual dysphoric disorder (PMDD) is characterized by a constellation of symptoms appearing regularly in the luteal phase of the cycle, and disappearing within a few days after the onset of menstruation (American Psychiatric Association 1994). Most researchers in the field regard irritability and anger as the cardinal symptoms of PMDD, but sadness, affect lability, and tension also are common complaints (see Steiner 1997; Freeman and Halbreich 1998; Eriksson 1999).

From the Department of Pharmacology, Göteborg University, Göteborg, Sweden.

Address correspondence to: Hoi-Por Ho, Department of Pharmacology, Göteborg University, POB 431, SE 40530 Göteborg, Sweden.

Received April 25, 2000; revised October 6, 2000; accepted October 18,2000
The hypothesis that ovarian steroids are of importance for the pathophysiology of PMDD gains support not only from the fact that the onset and disappearance of symptoms are linked to the reproductive cycle, but also from the findings that premenstrual complaints may be reduced by surgical ovariectomy and by druginduced inhibition of ovulation (see Backstrom and Hammarback 1991; Schmidt et al. 1998). Several observations suggest that PMDD subjects do not differ from controls with respect to serum levels of sex steroids, but with respect to how the brain reacts to these hormones. First, most studies suggest that replacing endogenous sex steroid secretion with exogenous hormones in the form of oral contraceptives is usually not an effective treatment for PMDD (Bancroft and Rennie 1993). Second, treatment with progesterone and/or estrogen after administration of an ovulation inhibitor has been shown to elicit PMDD-like symptoms in women with a history 
of PMDD, but not in controls (Schmidt et al. 1998). Third, women with a history of PMDD more often than other women experience PMDD-like symptoms when given gestagen intermittently during menopause as part of a hormonal replacement therapy (Bjorn et al. 1999).

Animal experiments suggest that the brain neurotransmitter serotonin exerts an inhibitory influence on irritability and aggression (see Eriksson and Humble 1990), and also that brain serotonergic neurotransmission is influenced by sex steroids (Rubinow et al. 1998). The hypothesis that serotonin may be involved in the regulation of premenstrual irritability lends strong support from studies showing that serotonin reuptake inhibitors very effectively reduce the symptoms of PMDD (Sundblad et al. 1992; Eriksson et al. 1995; Steiner et al. 1995; Yonkers et al. 1997; Wikander et al. 1998); moreover, whereas the serotonin precursor tryptophan has been shown to be superior to placebo for the treatment of PMDD (Steinberg et al. 1999), a reduction in serotonergic activity, by means of tryptophan depletion, leads to enhanced irritability in PMDD subjects (Menkes et al. 1994).

In order to further elucidate how the cycle-dependent irritability characterizing PMDD is influenced, e.g., by sex steroids and by serotonin, respectively, the introduction of an animal model of PMDD is highly warranted. The resident intruder paradigm is a socalled animal model of aggression, based on the observation that a rat that has been kept in the same cage for a certain time (i.e., the resident) will attack an unknown rat (i.e., the intruder) that is introduced into its domain (see Sheard 1991; Koolhaas and Bohus 1991).

The purpose of the present study was to investigate to what extent the aggressive behavior displayed by the resident female rat in the resident intruder model resembles the symptoms of PMDD in being: a) estrus cycle dependent; b) abolished by ovariectomy and reinstated by administration of female sex steroids; and c) reduced by administration of a serotonin reuptake inhibitor, fluoxetine.

\section{MATERIAL AND METHODS}

The study has been carried out in accordance with the Guide for the Care and Use of Laboratory Animals as adopted and promulgated by the National Institutes of Health and was approved by the Ethic Committee for Animal Experiments, Göteborg University, Sweden.

\section{Rats}

Female Wistar rats (200-240 g) were obtained from B\&K, Sollentuna, Sweden. The animals were housed under reversed 12/12 h light/dark cycle (light off 9 a.m.). Food and water were freely available except during experiments. In Experiments 1 and 2 (see below), the female rats were kept in group cages ( $4-5$ rats per cage) together with a sterilized male rat for at least one week, in order to induce pseudopregnancy, before being put in single cages. No experiments were undertaken until at least four weeks had elapsed after sexual experience, so that the pseudopregnancy had vanished and regular cyclicity had reappeared. In Experiment 3, the female rats were kept in group cages, with three animals per cage, from delivery and throughout the period of experiments. These rats had no sexual experience with a male rat before being used in the residentintruder experiments.

The female rats used as intruders in the three experiments were ovariectomized one week after delivery and housed in group cages ( $4-5$ rats per cage). They were not used until their surgical wounds were healed.

\section{Determination of Cycle Phase}

In Experiments 1 and 2, estrus cycle phase (metestrus, diestrus 1, diestrus 2, proestrus, estrus) was determined by microscopical examination of daily obtained vaginal smears. The non-receptive phases - metestrus, diestrus 1 and diestrus 2 (each phase lasting for approximately one day) - are characterized by the presence of leucocytes in the smears. Metestrus smears contain, in addition, some cornified epithelial cells, whereas vacuolated and nucleated epithelial cells can be found in diestrus smears. The receptive phases - proestrus, estrus (together one day in duration) - are characterized by thick smears of nucleated epithelial cells in proestrus and cornified epithelial cells in estrus, and, contrary to smears obtained in the non-receptive phases, smears from both receptive phases are free from leucocytes (for further details, see Mandl 1951). At the days of the experiment, the vaginal smears were obtained immediately after the encounter with intruder.

The occurrence of pseudopregnancy also was confirmed by means of vaginal smears. Pseudopregnancy lasts for around 13 days (Welschen et al. 1975), and is characterized by very thick mucus and a marked presence of leucocytes in the smears.

\section{Determination of Estrus Behavior}

In Experiment 3, the hormone-primed ovariectomized rats were tested with respect to estrus behavior to confirm the accuracy of the hormone dosage given. The estrus behavior typical for the proestrus and estrus phases, i.e., proceptivity (hop/darting and ear wiggling) and receptivity (lordosis), was assessed by placing the female rat in a cage inhabited by male rats and lightly stroking the female rat on the back. The male rats were prevented from mounting the female rat. The resident intruder experiment was undertaken two days after the rats had displayed estrus behavior; to ensure that the animals were 
not still in estrus phase, the estrus behavior test was performed also on the day of the aggression test, three hours before the resident intruder experiment was started.

\section{Resident Intruder Test}

Aggression was tested in dim white light ( $<2$ lux) between 2.30 p.m. and 5.30 p.m. (i.e., during the dark period) in the same room where the female rats were normally kept. The cage was moved from the rack to an observance table. In the case where the rats lived in group cages (Experiment 3), the two other female rats were removed before the test. After about $15 \mathrm{~min}$ of habituation, an ovariectomized female intruder (same size as the resident) was introduced for a period of $10 \mathrm{~min}$. An observer was scoring various aspects of aggression — 'attacks', 'attack-time', 'bites', 'on-top', 'on-top-time', and 'piloerection' - displayed by the resident vis-à-vis with the intruder. The attacks are of two types, lunge attack (jump at the intruder to topple it down), and lateral attack (on-toes and arched back, moves sideways against the intruder to push it over). A composite aggression score was computed as follows: Composite aggression $=($ number of attacks $)+0.2($ attack duration $(\mathrm{s}))+$ (number of bites) +0.2 (on-top duration(s)) + (piloerection) (Albert et al. 1991).

Piloerection was scored as 0 if absent, 2 if partial or if not lasting throughout the entire session, and 4 if complete and present for the entire session. Observations from Experiments 1 and 2 (and other experiments) however showed that piloerection never occurs without a following lateral attack and/or bite, suggesting that measurement of piloerection is redundant; thus, in the third experiment, piloerection was not registered. In Experiments 1 and 2, the rats were considered to be aggressive when they displayed at least one of the behaviors bite, lateral attack, or piloerection; in Experiment 3, they were defined as aggressive if they displayed lateral attack or bite. In Experiments 1 and 2, and in the first part of Experiment 3 (before ovariectomy), only rats displaying regular four-day cycles were tested in the resident intruder paradigm.

\section{Sterilization, Ovariectomy, and Hormone Priming}

Sterilization of male rats was done by ligation and incision of vasa deferentia during ketamine $(80 \mathrm{mg} / \mathrm{kg}$; Bayer AG) / xylazine (16 mg/kg; Warner Lambert Nordic $A B)$ anaesthesia. Ovariectomy of female rats was done by ligation of uterine tubes and removal of ovaries during anaesthesia (see above). In the third experiment, ovariectomized rats (residents) were primed with estradiol benzoate (estradiol-3-benzoate in oleate $5 \mathrm{mg}$ / $\mathrm{ml}$; diluted in sesame oil, $0.5 \mu \mathrm{g} / \mathrm{rat}$ in $0.1 \mathrm{ml}$, s.c.; Organon; $0 \mathrm{~h}$ ), estradiol (1, 3, 5 [10]-estratiene-3, 17 $\beta$-diol; $0.5 \mu \mathrm{g} / \mathrm{rat}$ in $0.1 \mathrm{ml}$ sesame oil, s.c.; Sigma Chemical Co;
$32 \mathrm{~h}$ ), and progesterone (4-pregnene-3, 10-dione; 0.5 $\mathrm{mg} / \mathrm{rat}$ in $0.1 \mathrm{ml}$ sesame oil s.c.; Sigma Chemical Co; 44 h). This hormone regimen has been found to induce a vaginal and behavioral cyclicity closely mirroring that of an intact rat (Ho et al. to be published).

\section{Locomotion Test}

Locomotor activity was assessed using photocell animal motility meters, based on eight soundproofed ventilated boxes (Kungsbacka Mät- och Reglerteknik AB, Fjärås, Sweden) connected to a computer (software from Kungsbacka Mät- och Reglerteknik AB, Fjärås, Sweden). The activity boxes have a floor area of $700 \times 700 \mathrm{~mm}$, and are equipped with two rows of photocells (totally 16 photocells). Locomotor activity is assessed by registration of the breaking of a sequence of beams, representing movement in a single direction (for details, see Ericson et al. 1991). The rats were tested for 60 minutes and were not habituated to the boxes before the test.

\section{Experimental Design}

In the first experiment, the resident intruder test was undertaken daily for four consecutive days, i.e., throughout an entire estrus cycle, in untreated animals. On which day of the cycle the first test was undertaken was random. The observer was not aware of the cycle phase of the animal.

In the second experiment, the resident intruder test was undertaken on the second day of the estrus cycle (i.e., on the first day of diestrus) only. In this experiment, rats found to be aggressive when tested in the diestrus phase at baseline were divided into two equally sized groups. When at least one estrus cycle had elapsed since the first aggression test, the two groups of rats were given daily injections of fluoxetine hydrochloride $(10 \mathrm{mg} / \mathrm{kg}$; i.p; dissolved in saline, $2 \mathrm{mg} / \mathrm{ml}$; donated by Eli Lilly \& Co.) or saline, respectively (totally five injections); the dose of fluoxetine given was based on previous behavioral and biochemical experiments reported in the literature (Perry and Fuller 1993; Rutter et al. 1994; Detke et al. 1995; Invernizzi et al.1996; Page et al. 1999; Zhang et al. 2000; Silva and Brandao 2000). The last injection was given $3 \mathrm{~h}$ before aggression was tested, i.e., on the first day of diestrus. The observer was not aware of the treatment given.

In the third experiment, the female rats were tested in four rounds of aggression tests. The first round defined two groups of rats as aggressive and non-aggressive, respectively, at baseline. The two groups were ovariectomized as described above; three weeks later, the second round of the resident intruder test was undertaken. Four days before the third round of aggression tests, the ovariectomized rats were primed with female sex steroids according to the procedure described above, with the 
first estrogen injection given around noon. This injection scheme was designed to achieve a day for behavioral testing - two days after the receptive phase induced by the hormone priming - that would correspond to diestrus 1 in normally cycling rats. One to two days after the third aggression test, the rats were primed again. Rats defined as aggressive at baseline, and being aggressive also in the third round, when primed with hormones, were divided into two groups; in addition to female sex steroids, one group was given daily injections of fluoxetine hydrochloride ( $10 \mathrm{mg} / \mathrm{kg}$; i.p.; dissolved in saline, $2 \mathrm{mg} / \mathrm{ml}$; totally four injections) whereas the other group was given saline (same regimen). The last injection was given three hours before the fourth aggression test, in a phase corresponding to the diestrus phase of normally cycling rats. In addition, another group of primed ovariectomized rats were divided into two groups, given the same scheme of injections with fluoxetine or saline, and tested for locomotor activity three hours after the last injection (see above).

\section{Statistics}

Data from resident intruder experiments are presented as medians with inter quartile range or with range. Groups were statistically compared with respect to aggression scores by means of Wilcoxon signed rank test in Experiment 1, and by means of Wilcoxon signed rank test and Mann-Whitney U test, respectively, in Experiments 2 and 3 . The proportions of aggressive rats in the groups were statistically compared using Fisher's exact test. $p<.05$ was considered statistically significant.

\section{RESULTS}

\section{Experiment 1}

Five of 14 rats with regular four-day estrus cycles did not display aggressive behavior at any phase of the cycle, and were hence excluded. The remaining nine rats
Table 1. Aggressive Behavior in Female Rats with Regular Four-day Cycles

\begin{tabular}{lcccc}
\hline & Estrus & Metestrus & Diestrus 1 & Diestrus 2 \\
\hline Median (iqr) & $0(0-0)$ & $19(6-28.5)$ & $17(7-20)$ & $11(2-27)$ \\
$x / n^{\mathrm{a}}$ & $0 / 9$ & $8 / 9$ & $7 / 9$ & $6 / 9$ \\
In comparison & & $p<.01^{\mathrm{b}}$ & $p<.05^{\mathrm{b}}$ & $p<.05^{\mathrm{b}}$ \\
$\quad$ to estrus & & $p<.001^{\mathrm{c}}$ & $p<.01^{\mathrm{c}}$ & $p<.01^{\mathrm{c}}$ \\
\hline
\end{tabular}

${ }^{\mathrm{a}} x=$ number of aggressive rats, $n=$ total number of rats.

${ }^{\mathrm{b}}$ Wilcoxon signed rank test (comparison of medians).

'Fischer's exact test (comparison of $\mathrm{x} / \mathrm{n}$ ).

iqr $=$ interquartile range.

were significantly more aggressive in the non-receptive phases of the cycle (metestrus, diestrus 1, diestrus 2) than in the receptive phases (proestrus and estrus) (see Table 1). When tested in the receptive phases, all rats displayed lordosis behavior when in contact with the intruding female.

\section{Experiment 2}

Eighteen of 30 rats with regular four-day estrus cycles were found to display aggressive behavior when tested in the diestrus phase of the cycle, and were randomly subjected to treatment with fluoxetine $(n=9)$ or saline $(n=9)$. After five daily injections, the total amount of aggressive behavior, and the number of rats defined as aggressive, were significantly lower in the group treated with fluoxetine than in the group given saline (see Table 2).

\section{Experiment 3}

Ovariectomy of 16 rats that had been defined as aggressive at baseline reduced the aggressive behavior of these animals so that they no longer differed from a group of 16 ovariectomized rats that had been defined as non-aggressive before ovariectomy. In the group of rats that had displayed aggressive behavior at baseline,

Table 2. Effect of Fluoxetine on Aggressive Behavior in Female Rats Tested in the Diestrus Phase

\begin{tabular}{lcccc}
\hline & & Baseline & Treatment & $\begin{array}{c}\text { Baseline vs. } \\
\text { Treatment }\end{array}$ \\
\hline Saline & Median (iqr) & $30(19.5-51.5)$ & $14(7.5-44.5)$ & $\mathrm{ns}^{\mathrm{d}}$ \\
& $x / n^{\mathrm{a}}$ & $9 / 9$ & $8 / 9$ & $\mathrm{~ns}^{\mathrm{c}}$ \\
Fluoxetine & Median (iqr) & $36(21.5-44.5)$ & $0(0-9)$ & $p<.05^{\mathrm{d}}$ \\
& $x / n^{\mathrm{a}}$ & $9 / 9$ & $3 / 9$ & $p<.01^{\mathrm{c}}$ \\
Saline vs. & & $\mathrm{ns}^{\mathrm{b}}$ & $p<.05^{\mathrm{b}}$ & \\
Fluoxetine & & $\mathrm{ns}^{\mathrm{c}}$ & $p<.01^{\mathrm{c}}$ & \\
\hline
\end{tabular}

${ }^{\mathrm{a}} x=$ number of aggressive rats, $n=$ total number of rats.

bMann-Whitney U-test (comparison of medians).

'Fischer's exact test (comparison of $x / n$ ).

dWilcoxon signed rank test (comparison of medians).

iqr $=$ interquartile range. 
before ovariectomy, hormone priming induced aggressive behavior two days after the rats had displayed estrus behavior, i.e., in a phase tentatively corresponding to the diestrus phase of normal animals. Hormone priming of the rats that were non-aggressive at baseline did not elicit aggression; administration of female sex steroids after ovariectomy hence reestablished a difference between the aggressive and non-aggressive group with respect to aggressive behavior (see Table 3).

The 11 rats in the aggressive group that were found to be aggressive when primed with hormones were then primed once more. Again the hormonal treatment induced aggressive behavior in a phase corresponding to diestrus; this hormone-induced aggression was however significantly lower in the subgroup given four daily injections with fluoxetine $(n=6)$ when compared to those given saline $(n=5)$ (see Table 4). Eight hormone-primed rats treated with four daily injections of fluoxetine $(n=4)$ or saline $(n=4)$ were tested in a locomotion test, revealing no significant difference in locomotion between fluoxetine (mean \pm SEM: $477 \pm 52$ counts) and saline (486 \pm 105 counts) treated animals (Student's t-test, $p=.9$ ).

\section{DISCUSSION}

The resident intruder model has been claimed to comprise all the elements of aggression displayed by a wild rat in an aggressive encounter with an intruder (Blanchard and Blanchard 1977). The present data suggest that the aggressive behavior displayed by the resident female vis-à-vis with an ovariectomized intruder in this paradigm is clearly cycle-dependent, with almost no aggressive behavior displayed during the receptive phases (proestrus and estrus) of the cycle, and marked aggressive behavior displayed during the non-receptive phases (metestrus and diestrus phases). Likewise, using other models of aggression, Calhoun (1962), Swanson and coworkers (Swanson et al. 1982), and Hood (1984) have reported that aggressive behavior in female rats may be cycle-dependent; in addition, estrus cycle-related variations in aggressive behavior have been demonstrated in mice (Hyde and Sawyer 1977), hamsters (Floody and Pfaff 1977), cows (Castellanos et al. 1992), and nonhuman primates (Hausfater and Skoblick 1985; Lisk and Nachtigall 1988; Rapkin et al. 1995).

Women with PMDD usually display marked irritability, anger, and affect lability during one to two weeks preceding the onset of menstruation, but no such symptoms from day 3-5 of the cycle and until ovulation. Several studies suggest that premenstrual complaints are triggered by the high mid-cycle levels of progesterone and/or estradiol, and appearing with a delay of approximately one week (or less) (Schmidt et al. 1998). Likewise, the cycle-dependent aggression displayed by female rats in the resident intruder paradigm occurs one day (i.e., $25 \%$ of the cycle) after serum levels of progesterone and estradiol are peaking (Smith et al. 1975), and in a phase of the cycle when conception cannot occur. Although the behavior displayed by the animals in this paradigm is usually referred to as 'aggression' rather than 'irritability' or 'anger', it is tempting to suggest that the neuroendocrine mechanisms underlying this cycle-related behavior in rats are related to those underlying the cycle-related irritability and anger that constitute the cardinal symptoms of PMDD.

Underlining the importance of sex steroids for the aggressive behavior displayed by female rats in the resident intruder paradigm, this behavior was effectively abolished by ovariectomy. Further supporting the relationship between this animal model and premenstrual irritability in humans, the symptoms of PMDD also

Table 3. Aggressive Behavior in Female Rats at Baseline, after Ovariectomy (OVX), and after Ovariectomy + Hormone Priming $(\mathrm{OVX} / \mathrm{H})$

\begin{tabular}{|c|c|c|c|c|c|c|}
\hline & & Baseline & OVX & OVX/H & $\begin{array}{l}\text { Baseline } \\
\text { vs. OVX }\end{array}$ & $\begin{array}{l}\text { OVX vs. } \\
\text { OVX/H }\end{array}$ \\
\hline Non-aggressive & $\begin{array}{c}\text { Median (iqr) } \\
x / n^{\mathrm{a}}\end{array}$ & $\begin{array}{r}0(0-0) \\
0 / 16\end{array}$ & $\begin{array}{c}0(0-20)^{\mathrm{e}} \\
3 / 16\end{array}$ & $\begin{array}{c}0(0-4) \\
1 / 16\end{array}$ & $\begin{array}{c}p<.05^{\mathrm{d}, \mathrm{e}} \\
\mathrm{ns}^{\mathrm{c}}\end{array}$ & $\begin{array}{l}\mathrm{ns}^{\mathrm{d}} \\
\mathrm{ns} \mathrm{s}^{\mathrm{c}}\end{array}$ \\
\hline Aggressive & $\begin{array}{c}\text { Median (iqr) } \\
x / n^{\mathrm{a}}\end{array}$ & $\begin{array}{c}25(20-37) \\
16 / 16\end{array}$ & $\begin{array}{c}2(0-14) \\
3 / 16\end{array}$ & $\begin{array}{c}16(3.5-27.5) \\
11 / 16\end{array}$ & $\begin{array}{l}p<.01^{\mathrm{d}} \\
p<.001^{\mathrm{c}}\end{array}$ & $\begin{aligned} \mathrm{ns}^{\mathrm{d}}(p<.05)^{\mathrm{f}} & <<.05^{\mathrm{c}}\end{aligned}$ \\
\hline $\begin{array}{c}\text { Non-aggressive } \\
\text { vs. aggressive }\end{array}$ & & $\begin{array}{l}p<.001^{\mathrm{b}} \\
p<.001^{\mathrm{c}}\end{array}$ & $\begin{array}{l}\mathrm{ns}^{\mathrm{b}} \\
\mathrm{ns}^{\mathrm{c}}\end{array}$ & $\begin{array}{l}p<.01^{\mathrm{b}} \\
p<.01^{\mathrm{c}}\end{array}$ & & \\
\hline
\end{tabular}

Rats displaying aggressive behavior at baseline $(n=16)$ were defined as 'aggressive'; rats not displaying aggressive behavior at baseline $(n=16)$ were defined as 'non-aggressive'.

${ }^{\mathrm{a}} x=$ number of aggressive rats, $n=$ total number of rats.

bann-Whitney U-test (comparison of medians).

'Fischer's exact t-test (comparison of $x / n$ ).

${ }^{\mathrm{d}}$ Wilcoxon signed rank test (comparison of medians).

'The aggression score in OVX rats is mainly due to the occurrence of playful behavior, like lunge-attack and on-top time, rather than aggressive behavior, like lateral attack and bite (see Discussion).

${ }^{\mathrm{f}} p$-value indicated within brackets: only the 13 rats not displaying aggression after ovariectomy are included in the calculation.

iqr $=$ interquartile range. 
Table 4. Effect of Fluoxetine on Aggressive Behavior in Hormone-Primed Ovariectomized Rats

\begin{tabular}{lcccc}
\hline & & $\begin{array}{c}\text { Before } \\
\text { Treatment }\end{array}$ & $\begin{array}{c}\text { After } \\
\text { Treatment }\end{array}$ & $\begin{array}{c}\text { Before vs. } \\
\text { After Treatment }\end{array}$ \\
\hline Saline & Median (range) & $25(19-47)$ & $22(9-60)$ & $\mathrm{ns}^{\mathrm{d}}$ \\
Fluoxetine & $x / n^{\mathrm{a}}$ & $5 / 5$ & $4 / 5$ & $\mathrm{~ns}^{\mathrm{c}}$ \\
& Median (range) & $16(10-39)$ & $0.5(0-7)$ & $p<.05^{\mathrm{d}}$ \\
Saline vs. fluoxetine & $x / n^{\mathrm{a}}$ & $6 / 6$ & $1 / 6$ & $p<.05^{\mathrm{c}}$ \\
& & $\mathrm{ns}$ & $p<.01^{\mathrm{b}}$ & \\
& & $\mathrm{ns}^{\mathrm{b}}$ & $(p=.08)^{\mathrm{c}}$ & \\
\hline
\end{tabular}

${ }^{\mathrm{a}} x=$ number of aggressive rats, $n=$ total number of rats.

bann-Whitney U-test (comparison of medians).

'Fischer's exact test (comparison of $x / n$ ).

${ }^{\mathrm{d}}$ Wilcoxon signed rank test (comparison of medians).

have been shown to be effectively reduced by ovariectomy, or by administration of an ovulation inhibitor (Muse et al. 1984; Backstrom and Hammarback 1991; Schmidt et al. 1998; Leather et al. 1999).

Notably, not all animals were aggressive at baseline; thus, approximately $30-60 \%$ of intact animals did not display aggression in any phase of the estrus cycle. In those animals that had displayed aggressive behavior during the diestrus phase at baseline, and subsequently had been ovariectomized, the aggressive behavior was revived by administration of female sex steroids in a regimen mimicking the secretion of estradiol and progesterone during a normal estrus cycle. In contrast, rats not displaying aggression in the diestrus phase before ovariectomy also failed to display aggression when exposed to exogenous sex steroids after removal of the ovaries. These observations strongly resemble those of Schmidt and co-workers (1998) that the symptoms of PMDD could be reinstated by exogenously administered sex steroids after pretreatment with an ovulation inhibitor in women with PMDD; in contrast, no symptom provocation was observed when sex steroids were given subsequently to an ovulation inhibitor to women with no history of premenstrual complaints.

The finding that not all female Wistar rats display aggressive behavior in the resident intruder paradigm at baseline is in line with previous studies (Albert et al. 1993). The observation that rats being aggressive before ovariectomy were those that displayed aggressive behavior also when primed with exogenous hormones suggest that the difference between aggressive and non-aggressive rats is not due to differences in serum levels of estradiol or progesterone, but to a difference in the responsiveness of the brain to the influence of these hormones. Further studies are warranted in order to clarify the mechanisms underlying these inter-individual differences in behavior, and to establish if they are due to genetical differences, or are the result of environmental factors, such as the intrauterine milieu (see Vom Saal 1991) or social experiences (see Koolhaas and Bohus 1991).
Further supporting the notion that similar mechanisms are involved in the aggression displayed during the diestrus phase by female rats in the resident intruder paradigm, and in the irritability displayed premenstrually by women with PMDD, not only the latter (Sundblad et al. 1992; Eriksson et al. 1995; Steiner et al. 1995; Yonkers et al. 1997) but also the former phenomenon is markedly reduced by treatment with serotonin reuptake inhibitors. Supporting the notion that the effect of fluoxetine observed in this experiment was indeed due to serotonin reuptake inhibition, we have recently observed a similar effect when using another serotonin reuptake inhibitor, paroxetine (Ho et al. to be published).

Notably, not only the aggression displayed in the diestrus phase by intact female rats was reduced by fluoxetine, but also that elicited by exogenous sex steroids in ovariectomized animals. This finding suggests that serotonin reuptake inhibitors may be useful for the treatment of gestagen-induced PMDD-like side effects in menopausal women on hormone replacement therapy (Hammarback et al. 1985; Magos et al. 1986); interestingly, recent studies suggest that these side-effects are particularly common in women with a history of PMDD (Bjorn et al. 1999). We are currently exploring the possible effect of serotonin reuptake inhibitors on gestagen-induced dysphoria in menopausal women.

When used for PMDD, the onset of action of serotonin reuptake inhibitors is much shorter than in depression, with a clear-cut reduction in symptoms within four days of treatment (or even faster) (Sundblad et al. 1993; Steiner et al. 1997; Wikander et al. 1998; Freeman et al. 1999). In line with this observation, in the present experiment, chronic administration of fluoxetine was not required in order to reduce sex steroid-related aggression.

The observation that fluoxetine reduces aggressive behavior in female rats is in line with previous studies suggesting that serotonin depletion may increase aggression in rodents (see Eriksson and Humble 1990), and that serotonin reuptake inhibitors reduce aggressive 
behavior in some (but not all) animal models of aggression (Molina et al. 1987; Olivier and Mos 1992; Fuller 1996; Mitchell and Redfern 1997; Sanchez and Meier 1997; Matto et al. 1998). That the effect of fluoxetine in the present experiments was due to a specific effect on aggressive behavior rather than to a reduction in locomotor activity gains support from the experiment in which locomotion in fluoxetine-treated animals was tested and found to be no different from that of controls.

Aggression is not the only form of behavior that is both cycle-related and responsive to treatment with serotonin reuptake inhibitors. Marvan and co-workers (Marian et al. 1996) have thus previously reported that the immobility displayed by female rats in a so-called animal model of depression (the swimming immobility test) is more pronounced in the diestrus phase than in the estrus phase of the cycle, and that the immobility in the diestrus phase is reduced by treatment with a serotonin reuptake inhibitor, clomipramine. Tentatively, serotonin may be a key factor in mediating the effects of cycle-related changes in hormonal levels on various aspects of behavior; supporting this notion, we recently showed that administration of a serotonin reuptake inhibitor reduces sexual receptivity in the estrus phase of normally cycling, female rats (Matuszczyk et al. 1998; see also Uphouse et al. 1991).

A few technical comments are warranted. Albert and co-workers (1991) have reported that aggressive behavior is exaggerated in female rats that have experienced pseudopregnancy; for this reason, the rats used in the first and second experiments had all been the subjects of one period of pseudopregnancy before the resident intruder experiments were started. In subsequent experiments in our laboratory, we have however observed that pseudopregnancy is not a prerequisite for estrus cycle-related aggression in the resident intruder paradigm (cf. Hood 1984); thus, the rats used in the third experiment had no sexual experience before being used in the resident intruder experiment. Another difference between the experimental conditions of the first and second experiments on the one hand, and the third experiment on the other, is that the resident rats were kept in individual cages in the first two experiments, and in groups of three in the third. The clear-cut aggression displayed by many of the rats included in the third experiment illustrates that neither a previous period of pseudopregnancy nor keeping the animals in single cages is necessary for the expression of cycle-related aggression. However, although the intensity and quality of the aggressive behavior at baseline displayed by the aggressive rats in the third experiment was indistinguishable from that displayed by the animals in the first two experiments, it is noteworthy that the percentage of rats displaying aggressive behavior was lower in the third experiment (30\% vs. $65 \%$ ). Additional studies are required in order to establish if this difference may be due to the preceding pseudopregnancy and/or to keeping the rats in single cages.

If succeeding in topple the intruder, an aggressive rat can spend considerable time on-top the intruder; if not succeeding in topple the intruder, the time is often used for attacks instead. To quantify aggressive behavior, a composite aggression score, taking different aspects of aggressive behavior into consideration, is obviously required. In this paper, a technique for calculating aggression comprising the parameters 'attacks', 'attack-time', 'bites', 'on-top', 'on-top-time', and 'piloerection' was used (Albert et al. 1991). 'Lunge attacks' and 'on-top-time' may however occur also in non-aggressive rats, e.g., in young animals displaying rough and tumble play, and elicits another kind of response than more genuine aggression. To be defined as aggressive in this study, the animals hence had to display at least one of the behaviors 'bite', 'lateral attack', or 'piloerection'. After ovariectomy, very few of the previously aggressive rats displayed these aspects of aggression, but several of them displayed 'on-top' behavior and 'lunge attacks'. This is the reason why ovariectomized rats differ significantly from hormonally primed animals with respect to number of aggressive animals, but not with respect to total aggression score. Only ovariectomized rats were used as intruders; whereas a few ovariectomized resident rats displayed aggressive behavior, ovariectomized intruders never did (> 500 observations; Ho et al. unpublished observation).

In conclusion, we have shown that the aggression displayed by female rats of the Wistar strain in the resident intruder paradigm is cycle-dependent, that it is reduced by ovariectomy, and that it can be reinstated by administration of estradiol and progesterone in a regimen mimicking the normal cyclical hormone secretion. We have also shown that there are inter-individual differences in aggressive behavior within a group of Wistar rats, those displaying aggressive behavior at baseline also responding with an increase in aggressive behavior when exposed to exogenous female sex steroids after ovariectomy. Finally, we have shown that short-term treatment with a selective serotonin reuptake inhibitor, fluoxetine, reduces both the aggressive behavior displayed by intact rats in the diestrus phase of the cycle, and the aggressive behavior elicited by administration of sex steroids in ovariectomized animals. It is suggested that the cycle-dependent aggressive behavior displayed by female rats in resident intruder paradigm may be the result of mechanisms related to those eliciting irritability and anger premenstrually in women with PMDD; tentatively this model may hence be used to elucidate the neuroendocrine mechanisms triggering premenstrual irritability, and the detailed mode of action of serotonin reuptake inhibitors when used for this indication. 


\section{ACKNOWLEDGMENTS}

This study was supported by the Foundation of Knut and Alice Wallenberg, AstraZeneca, the Lundberg Foundation, the Swedish Medical Research Council (grant no. 8668), the Foundation of the Söderström-Königska Nursing Home, and the Foundation of Fredrik Thuring. Fluoxetine was generously provided by Eli Lilly \& Co, Indianapolis, U.S. Excellent technical assistance was provided by Gunilla Bourghardt and Inger Oscarsson.

\section{REFERENCES}

Albert DJ, Jonik RH, Watson NV, Moe IV, Walsh ML (1991): Aggression by a female rat cohabitating with a sterile male: Termination of pseudopregnancy does not abolish aggression. Physiol Behav 50(3):519-523

Albert DJ, Jonik RH, Walsh ML (1993): Influence of combined estradiol and testosterone implants on the aggressiveness of nonaggressive female rats. Physiol Behav 53(4):709-713

American Psychiatric Association (1994): Diagnostic and Statistical Manual of Mental Disorders, $4^{\text {th }}$ ed. Washington DC, APA Press

Backstrom T, Hammarback S (1991): Premenstrual syndrome - psychiatric or gynaecological disorder? Ann Med 23(6):625-633

Bancroft J, Rennie D (1993): The impact of oral contraceptives on the experience of perimenstrual mood, clumsiness, food craving and other symptoms. J Psychosom Res 37(2):195-202

Blanchard RJ, Blanchard CD (1977): Aggressive behavior in the rat. Behav Biol 21(2):197-224

Bjorn I, Bixo M, Nojd-Strand K, Nyberg S, Backstrom T (1999): Negative mood induction by progestagen is related to a history of premenstrual syndrome. Acta Physiol Scand 167(2):A3-A28

Calhoun JB (1962): The Ecology and Sociology of the Norway Rat. U.S. Health Publication No. 1008. Washington DC, U.S. Printing Office

Castellanos F, Orihuela A, Galina CS (1992): Aggressive behaviour in oestrus and dioestrus dairy cows and heifers. Vet Rec 131(22):515

Detke MJ, Rickels M, Lucki I (1995): Active behaviors in the rat forced swimming test differentially produced by serotonergic and noradrenergic antidepressants. Psychopharmacology 121:66-72

Ericson E, Samuelsson J, Ahlenius S (1991): Photocell measurements of rat motor activity. A contribution to sensitivity and variation in behavioral observations. J Pharmacol Methods 25(2):111-122

Eriksson E, Humble M (1990): Serotonin in psychiatric pathophysiology. A review of data from experimental and clinical research. In Pohl R, Gershon S (eds), The Biological Basis of Treatment. Prog Basic Clin Pharmacol. Basel, Karger, pp 66-119

Eriksson E, Hedberg MA, Andersch B, Sundblad C (1995): The serotonin reuptake inhibitor paroxetin is superior to the noradrenaline reuptake inhibitor maprotiline in the treatment of premenstrual syndrome. Neuropsychopharmacology 12(2):167-176

Eriksson E (1999): Serotonin reuptake inhibitors for the treatment of premenstrual dysphoria. Int Clin Psychopharmacol 14(Suppl 2):S27-S33

Floody OR, Pfaff DW (1977): Aggressive behavior in female hamsters: The hormonal basis for fluctuations in female aggressiveness correlated with estrus state. J Comp Physiol Psychol 91(3):443-464

Freeman EW, Halbreich U (1998): Premenstrual syndromes. Psychopharmacol Bull 34(3):291-295

Freeman EW, Rickels K, Arredondo F, Kao LC, Pollack SE, Sondheimer SJ (1999): Full- or half-cycle treatment of severe premenstrual syndrome with a serotonergic antidepressant. J Clin Psychopharmacol 19(1):3-8

Fuller RW (1996): Fluoxetine effects on serotonin function and aggressive behavior. Ann N Y Acad Sci 794:90-97

Hammarback S, Backstrom T, Holst J, Von Schoultz B, Lyrenas $S$ (1985): Cyclical mood changes as in the premenstrual tension syndrome during sequential estrogen-progestagen postmenopausal replacement therapy. Acta Obstet Gynecol Scand 64(5):393-397

Hausfater G, Skoblick B (1985): Perimenstrual behavior changes among female yellow baboons (Papio cynocephalus): Some similarities to premenstrual syndrome in women. Am J Primatol 9(3):165-172

Hood KE (1984): Aggression among female rats during the estrus cycle. In Alan R (ed), Biological Perspectives on Aggression. New York, Alan R. Liss, Inc, pp 181-188

Hyde JS, Sawyer TF (1977): Estrus cycle fluctuations in aggressiveness of house mice. Hormones Behav 9(3): 290-295

Invernizzi R, Bramante M, Samanin R (1996): Role of 5-HT $\mathrm{H}_{1 \mathrm{~A}}$ receptors in the effects of acute and chronic fluoxetine on extracellular serotonin in the frontal cortex. Pharmacol Biochem Behav 54(1):143-147

Koolhaas JM, Bohus B (1991): Animal model of human aggression. In Boulton A, Baker G, Martin-Iverson M (eds), Animal Models in Psychiatry. II. Totowa, The Humana Press Inc, pp 249-271

Leather AT, Studd JW, Watson NR, Holland EF (1999): The treatment of severe premenstrual syndrome with goserelin with and without 'add-back' estrogen therapy: A placebo-controlled study. Gynecol Endocrinol 13(1):48-55

Lisk RD, Nachtigall MJ (1988): Estrogen regulation of agonistic and proceptive responses in the golden hamster. Hormones Behav 22(1):35-48

Magos AL, Brewster E, Singh R, O'Dowd T, Brincat M, Studd JW (1986): The effects of norethisterone in postmenopausal women on oestrogen replacement therapy: A model for the premenstrual syndrome. $\mathrm{Br} \mathrm{J}$ Obstet Gynaecol 93(12):1290-1296

Mandl AM (1951): The phases of the oestrous cycle in the adult white rat. J Exp Biol 28:576-584

Marvan ML, Chavez-Chavez L, Santana S (1996): Clomipramine modifies fluctuations of forced swimming immobility in different phases of the rat estrus cycle. Arch Med Res 27(1):83-86

Matto V, Skrebuhhova T, Allikmets L (1998): The effect of antidepressants on rat aggressive behavior in the elec- 
tric footshock and apomorphine-induced aggressiveness paradigms. Methods Find Exp Clin Pharmacol 20(4):329-337

Matuszczyk JV, Larsson K, Eriksson E (1998): Subchronic administration of fluoxetine impairs estrus behavior in intact female rats. Neuropsychopharmacology 19(6):492498

Menkes DB, Coates DC, Fawcett JP (1994): Acute tryptophan depletion aggravates premenstrual syndrome. J Affect Disord 32(1):37-44

Mitchell PJ, Redfern PH (1997): Potentiation of the timedependent, antidepressant-induced changes in the agonistic behavior of resident rats by the 5-HT1A receptor antagonist, WAY-100635. Behav Pharmacol 8(6-7):585606

Molina V, Ciesielski L, Gobaille S, Isel F, Mandel P (1987): Inhibition of mouse killing behavior by serotonin-mimetic drugs: Effects of partial alterations of serotonin neurotransmission. Pharmacol Biochem Behav 27(1):123-131

Muse KN, Cetel NS, Futterman LA, Yen SC (1984): The premenstrual syndrome. Effect of "medical ovariectomy". N Engl J Med 311(21):1345-1349

Olivier B, Mos J (1992): Rodent models of aggressive behavior and serotonergic drugs. Prog Neuropsychopharmacol Biol Psychiatry 16(6):847-870

Page ME, Detke MJ, Dalvi A, Kirby LG, Lucki I (1999): Serotonergic mediation of the effects of fluoxetine, but not desipramine, in the rat forced swimming test. Psychopharmacology 147:162-167

Perry KW, Fuller RW (1993): Extracellular 5-hydroxytryptamine concentration in rat hypothalamus after administration of fluoxetine plus L-5-hydroxytryptophan. J Pharm Pharmacol 45:759-761

Rapkin AJ, Pollack DB, Raleigh MJ, Stone B, McGuire MT (1995): Menstrual cycle and social behavior in vervet monkeys. Psychoneuroendocrinology 20(3):289-297

Rubinow DR, Schmidt PJ, Roca CA (1998): Estrogen-serotonin interactions: Implications for affective regulation. Biol Psychiatry 44(9):839-850

Rutter JJ, Gundlah C, Auerbach SB (1994): Increase in extracellular serotonin produced by uptake inhibitors is enhanced after chronic treatment with fluoxetine. Neurosci Lett 171(1-2):183-186

Sanchez C, Meier E (1997): Behavioral profiles of SSRIs in animal models of depression, anxiety and aggression. Are they all alike? Psychopharmacology (Berl) 129(3): 197-205

Schmidt PJ, Nieman LK, Danceau MA, Adams LF, Rubinow DR (1998): Differential behavioral effects of gonadal steroids in women with and in those without premenstrual syndrome. N Engl J Med 338(4):209-216

Sheard MH (1991): Methods for drug studies in aggressive behavior. In Boulton A, Baker G, Martin-Iverson M (eds), Animal Models in Psychiatry. II. Tutowa, The Humana Press Inc, pp 233-248

Silva RC, Brandao ML (2000): Acute and chronic effects of gepirone and fluoxetine in rats tested in the elevated plus-maze: An ethological analysis. Pharmacol Biochem Behav 65:209-216

Smith MS, Freeman ME, Neill JD (1975): The control of proges- terone secretion during the estrus cycle and early pseudopregnancy in the rat: Prolactin, gonadotropin and steroid levels associated with rescue of the corpus luteum of pseudopregnancy. Endocrinology 96(1):219-226

Steinberg S, Annable L, Young SN, Liyanage N (1999): A placebo-controlled study of the effects of L-tryptophan in patients with premenstrual dysphoria. Adv Exp Med Biol 467:85-88

Steiner M, Steinberg S, Stewart D, Carter D, Berger C, Reid R, Grover D, Streiner D (1995): Fluoxetine in the treatment of premenstrual dysphoria. Canadian fluoxetine/ premenstrual dysphoria collaborative study group. $\mathrm{N}$ Engl J Med 332(23):1529-1534

Steiner M (1997): Premenstrual syndromes. Annu Rev Med 48:447-455

Steiner M, Korzekwa M, Lamont J, Wilkins A (1997): Intermittent fluoxetine dosing in the treatment of women with premenstrual dysphoria. Psychopharmacol Bull 33(4):771-774

Sundblad C, Modigh K, Andersch B, Eriksson E (1992): Clomipramine effectively reduce premenstrual irritability and dysphoria: A placebo-controlled trial. Acta Psychiatr Scand 85(1):39-47

Sundblad C, Hedberg MA, Eriksson E (1993): Clomipramine administered during the luteal phase reduces the symptoms of premenstrual syndrome: A placebo-controlled trial. Neuropsychopharmacology 9(2):133-145

Swanson HH, van de Poll NE, van Pelt J (1982): Influence of the estrus cycle on heterosexual aggression in two strains of rats (S3 and WEzob). Hormones Behav 16(4): 395-403

Uphouse L, Salamanca S, Caldarola-Pastuszka M (1991): Gender and estrus cycle differences in the response to the 5-HT1A agonist 8-OH-DPAT. Pharmacol Biochem Behav 40(4):901-906

Vom Saal FS (1991): Prenatal gonadal influences on mouse sociosexual behaviours. In Haug M, Brain PF, Aron C (eds), Heterotypical Behaviour in Man and Animals. London, Chapman and Hall, pp 42-70

Welschen R, Osman P, Dullaart J, de Greef WJ, Uilenbroek JT, de Jong FH (1975): Levels of follicle-stimulating hormone, luteinizing hormone, oestradiol- $17 \beta$ and progesterone, and follicular growth in the pseudopregnant rat. J Endocr 64:37-47

Wikander I, Sundblad C, Andersch B, Dagnell I, Zylberstein D, Bengtsson F, Eriksson E (1998): Citalopram in premenstrual dysphoric disorder: Is intermittent treatment more effective than continuous drug administration? J Clin Psychopharmacol 18(5):390-398

Yonkers KA, Halbreich U, Freeman E, Brown C, Endicott J, Frank E, Parry B, Pearlstein T, Severino S, Stout A, Stone A, Harrison W (1997): Symptomatic improvement of premenstrual dysphoric disorder with sertraline treatment. A randomized controlled trial. Sertraline Premenstrual Dysphoric Collaborative Study Group. JAMA 278(12):983-988

Zhang Y, Raap DK, Garcia F, Serres F, Ma Q, Battaglia G, Van de Kar LD (2000): Long-term fluoxetine produces behavioral anxiolytic effects without inhibiting neuroendocrine responses to conditioned stress in rats. Brain Res 855:58-66 